\title{
What is a systems approach?
}

Written by: Daniel Catalan, OECD Observer

Last update: 22 June 2018

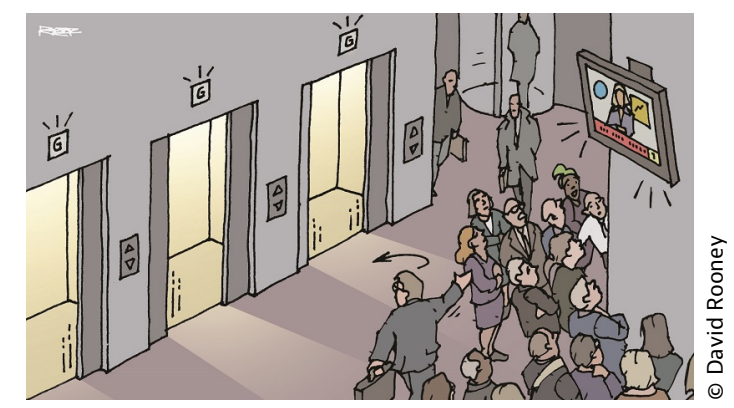

A systems approach can be applied to more complex administrative challenges,from transport and tourism to the environment.

The ancient Greek philosopher Aristotle said that "the whole is greater than the sum of its parts". He could have been describing a systems approach, which makes organisations more functional by looking at big-picture processes and practices. A systems approach can save money too.

Imagine a newly opened office building with 30 stories and only three lifts. Frustrated employees complain to the building's management about having to wait too long during rush hour. The lifts are sped up a little with manual operators. But employees are still unhappy.

So, management considers other solutions. One suggestion is to replace the outdated control device with one that offers a mix of express stops and local ones -costing US $\$ 5,000$. Another suggestion is to install a new lift, costing much more at US $\$ 60,000$. But then, a staff member named Anna suggests a clever alternative that would only cost US $\$ 300$. She argues that the source of frustration in waiting for the lift is boredom rather than the delay itself. Management tests the idea, and installs a television monitor in the lobby to entertain workers while they wait for the lift. The complaints fade away.

This is what the systems approach is about. Rather than treat a problem in a vacuum, it is viewed within a greater whole. Taking a holistic view of the problem, Anna and her colleagues shared their perspectives and finally came up with a workable and effective solution. 
Anna's solution may have only concerned an elevator, but it is an approach that can be applied far more widely to more complex administrative challenges, from transport and tourism to the environment. Some of these situations are described in Systems Approaches to Public Sector Challenges, an OECD report that provides examples of systems strategies in action. Take Canada, for example. Toronto's municipal government used a systems approach to deal with how the sharing economy would disrupt hospitality and transportation. An innovation hub called MaRS Solution Lab was recruited to research the sharing economy. They interviewed experts from the public and private sectors, as well as taxi drivers and hotel employees affected by sharing economy competitors such as Uber and AirBnB. The goal was to better understand how the new system worked both for and against traditional businesses, and to use the collected data to help government achieve balance when devising their regulatory approach.

Another example comes from the prime minister's office in Finland, which in collaboration with a Nordic think tank called Demos Helsinki, combined systems and design-thinking approaches to create and implement experiments on universal basic income. Facing severe time and budgetary restrictions, the Finnish government devised tests to gauge which methods of distributing basic income to the public would be the most effective, using small control groups of recipients. The Finnish government and Demos Helsinki reviewed relevant practices and interviewed experts from the public, private and volunteer sectors. By working together to design the tests, lawyers, bureaucrats and social scientists were collaborating and exchanging information towards a shared goal for the first time. The process of creating the tests was seen as a way to strengthen the links between citizens, end-users, stakeholders and policy designers. In addition, these endeavours attracted attention towards the cause of basic income, inspiring more studies on a subject in which Finland has positioned itself as an international leader.

A systems approach brings together interviews, dialogue, openness to perspectives from public and private sectors, and people at all levels of an institution's hierarchy. Although Aristotle could never have anticipated Anna's dilemma with the lift, the disruption of the service industry by the sharing economy, nor the need for and concept of a universal basic income, his point holds true that an understanding of all parts within a system make complex problems more easily solvable.

Share article and links: http://oe.cd/27y

\section{References}

Systems Approaches to Public Sector Challenges http://dx.doi.org/ 10.1787/9789264279865-en 
Marjukka Turunen (2017), "Basic income: An answer to social security problems?", in OECD Yearbook 2017. http://www.oecd.org/forum/ oecdyearbook/basic-income-an-answer-to-social-security-problems.htm

Read "Basic income: An answer to social security problems?" http:// www.oecd.org/social/basic-income-an-answer-to-social-securityproblems.htm

Chen, Gordon K.C., "What is the systems approach?”, Interfaces, Nov. 1975, Vol 6. No. 1 https://www.jstor.org/stable/25059250?seq=1\#page_scan_tab_contents 